\title{
The Application of Mean-Variance Model in Risk Measurement
}

\author{
Pei-Zhi WANG \\ Shandong University of Finance and Economics \\ Jinan, China \\ wpzmail@126.com
}

\author{
Yu-Xin ZHAO* \\ Shandong University of Finance and Economics \\ Jinan, China \\ 723797175@qq.com
}

\author{
Ling-Xi CHU \\ Shandong University of Finance and Economics \\ Jinan, China \\ clx0459@163.com
}

\begin{abstract}
This paper applies the method of mathematical statistics based on the Markowitz Mean Variance Model to choose portfolio. The main purpose of the paper is to explore the application of the Mean-Variance Model in risk measurement, and use the Mean-Variance Model to select the investment assets to reduce the losses caused by the risks. Therefore, the formulas of mean and variance are deduced and discussed according to different types of securities assets, and the application of the basic Mean-Variance Model in the Chinese stock market is empirically analyzed. Finally, it is concluded that when investors invest securities assets in the financial market, they can use the mathematical model to conduct risk measurement analysis. The main contribution of the paper is to choose the variance or standard deviation to measure the size of the risk. This method is simple and clear, and can reflect the risk information precisely.
\end{abstract}

Keywords-Mean-Variance Model; risk measurement; yield; uncertainty risk

\section{INTRODUCTION}

At present, a large number of securities investors are investing in the financial market. With the increasing expansion of the financial market, the globalization of economic development continues to advance, at the same time, financial risks are also growing. The measurement of market risk has become the foundation and core of market risk management. So the risk metric is especially important in the investment choice of the portfolio. When securities investors invest in risky assets, they first need to consider two important aspects: expected yield and risk. So how to determine the risk and profitability of the portfolio, how to play the game between these two indicators for optimal asset selection and distribution is a problem that market investors need to pay attention to.

In 1952, Markowitz proposed the mean variance model, introduced the expectation and variance theory in statistics into the study of portfolio investment. Markowitz assumes that the return on financial assets follows a normal distribution. Because the variance has good statistical characteristics, it is convenient and easy to understand. It has been widely used in securities asset investment, which also promotes the portfolio theory based on the mean variance model to become the core in the modern investment theory, Markowitz is also known as the pioneer of modern investment theory. [1]

\section{MODEL}

\section{A. Hypothesis}

1. Assuming that the returns of each security are subject to a normal distribution, the degree of association between them can be expressed by covariance or correlation coefficient.

2 . The investor measures the overall level of future real rate of return by the expected rate of return, and estimates the risk of the portfolio based on the variance or standard deviation of the expected rate of return of the security. [2]

3. Assume that the securities market is an effective market. The price of securities assets reflects all the information of the securities market. [5]

4. Other factors such as tax and transaction costs at the time of investment are not considered. [6]

5. Investors are risk avoiders.

\section{B. Calculation}

- Overall mode

$\left\{\begin{array}{l}\text { Min: } \sum_{i=1}^{n} \sum_{j=1}^{n} X_{i} X_{j} \sigma_{i j}=\sigma_{p}^{2} \\ \text { Max: } \sum_{i=1}^{n} X_{i} R_{i}=R_{p} \\ \text { s.t.: } \sum_{i=1}^{n} X_{i}=1\end{array}\right.$

$\mathrm{X}_{\mathrm{i}}=$ Proportion of the $i$ security asset

$\mathrm{R}_{\mathrm{i}}=$ Yield of the $i$ security asset

$\sigma_{i}=$ Covariance of securities assets $i$ and $j$

$\sigma_{\mathrm{p}}^{2}=$ Portfolio variance

$\mathrm{R}_{\mathrm{p}}=$ Portfolio yield

- Determination of a single security 


$$
\begin{aligned}
& \left\{\begin{array}{l}
E(R)=\sum_{i=1}^{n} P_{i} R_{i} \\
\sigma=\sqrt{\sum_{i=1}^{n}\left[R_{i}-E\left(R_{i}\right)\right]^{2} P_{i}}
\end{array}\right. \\
& \mathrm{P}_{\mathrm{i}}=\text { Probability of the rate of return } \\
& \mathrm{R}_{\mathrm{i}}=\text { Observed rate of return } \\
& \mathrm{E}(\mathrm{R})=\text { Expected rate of return } \\
& \sigma=\text { Expected standard deviation }
\end{aligned}
$$

In determining the risk of a portfolio, it is necessary to introduce the concept of covariance and correlation coefficients in statistics. Covariance is an important concept in statistics. It is used to represent the correlation between two variables. It is a key indicator for determining the variance of the portfolio's yield. If the value of the covariance is greater than zero, it indicates that the returns of securities $A$ and securities $B$ tend to change in the same direction. If the value of the covariance between the two securities is less than zero, it indicates that the returns of the two securities have a tendency to change in opposite directions.

If the covariance is normalized, a better descriptive parameter can be obtained: the correlation coefficient, the value of the correlation coefficient ranges from -1 to +1 , which indicates the degree of correlation between the two securities. [3][4]

$$
\begin{aligned}
& \left\{\begin{array}{l}
\sum_{i=1}^{n} X_{i} R_{i}=R_{p} \\
\operatorname{cov}\left(R_{A}, R_{B}\right)=\frac{1}{M} \sum_{i=1}^{M}\left[R_{A_{i}}-E\left(R_{A}\right)\right]\left[R_{B_{i}}-E\left(R_{B}\right)\right] \\
r_{A B}=\frac{\operatorname{cov}\left(R_{A}, R_{B}\right)}{\sigma\left(R_{A}\right) \sigma\left(R_{D}\right)}
\end{array}\right. \\
& \operatorname{cov}\left(\mathrm{R}_{\mathrm{A}}, \mathrm{R}_{\mathrm{B}}\right)=\text { Covarience of the yields of two securities } A \text { and } B \\
& \mathrm{r}_{\mathrm{AB}}=\text { Correlation coefficient between } A \text { and } B \text { securities }
\end{aligned}
$$

\section{CASE ANALYSIS}

According to the mean variance model, the following five SSE A shares were selected for analysis: Shanghai Pudong Development Bank (600000), Star Power (600101), Shanghai
Port Group (600018), Ningbo Construction Engineering (601789), and North Mining Technology (600980). And choose the best portfolio among the five stocks. The yield is taken from the quarterly data from 2013 to 2016 for a total of 16 quarters.

TABLE I. SSE A SHARES OF FIVE STOCKS FROM 13 TO 16 QUARTERLY YIELDS

\begin{tabular}{|c|c|c|c|c|c|}
\hline Share & $\mathbf{( 6 0 0 0 0 0 )}$ & $\mathbf{( 6 0 0 1 0 1 )}$ & $\mathbf{( 6 0 0 0 1 8 )}$ & $\mathbf{( 6 0 1 7 8 9 )}$ & (600980) \\
\hline Yield\% quarter of 16 & 16.35 & 4.32 & 11.38 & 8.15 & 7.38 \\
\hline 3th quarter of 16 & 12.86 & 4.54 & 6.6 & 5.57 & 3.69 \\
\hline 2th quarter of 16 & 8.59 & 2.48 & 4.82 & 3.84 & 2.55 \\
\hline 1th quarter of 16 & 4.5 & 1.6 & 2.03 & 2.22 & 1.18 \\
\hline 4th quarter of 15 & 18.82 & 4.79 & 11.53 & 8.14 & 8.18 \\
\hline 3th quarter of 15 & 14.37 & 4.7 & 8.08 & 6.46 & 0.81 \\
\hline 2th quarter of 15 & 9.37 & 2.53 & 5.58 & 4.18 & 0.14 \\
\hline 1th quarter of 15 & 4.47 & 1.52 & 2.72 & 2.58 & 0.69 \\
\hline 4th quarter of 14 & 21.02 & 5.47 & 13.13 & 8.68 & -11.68 \\
\hline 3th quarter of 14 & 15.92 & 6.4 & 9.2 & 6.54 & 1.23 \\
\hline 2th quarter of 14 & 10.52 & 3.04 & 5.77 & 4.38 & 0.27 \\
\hline 1th quarter of 14 & 5.09 & 1.51 & 2.85 & 2.72 & 0.58 \\
\hline 4th quarter of 13 & 21.53 & 9.9 & 10.76 & 11.82 & 5.55 \\
\hline 3th quarter of 13 & 15.93 & 12.91 & 8.14 & 7.65 & 6.64 \\
\hline 2th quarter of 13 & 10.45 & 9.28 & 5.2 & 5.36 & 1.32 \\
\hline 1th quarter of 13 & 4.89 & 1.33 & 2.11 & 2.77 & 0.11 \\
\hline
\end{tabular}


According to the mean variance model formula, using the Excel calculation function; we can calculate the expected yield and standard deviation of each stock:
Suppose the ratio of the two stocks is one-half. The five shares are represented by A, B, C, D, E respectively.

TABLE II. EXPECTED RATE OF RETURN AND ST ANDARD DEVIATION OF FIVE STOCKS OF SSE A SHARES

\begin{tabular}{|c|c|c|c|c|c|}
\hline & A & B & $\boldsymbol{C}$ & $\boldsymbol{D}$ & \\
\hline$E(\mathrm{R})$ & 12.17 & 4.77 & 6.87 & 5.69 & 1.79 \\
\hline$\sigma$ & 5.82 & 3.39 & 3.60 & 2.71 & 4.53 \\
\hline
\end{tabular}

According to the mean variance model formula, using the Excel calculation function, the covariance and correlation coefficient between the two stocks are calculated separately:

TABLE III. COVARIANCE AND CORRELATION COEFFICIENT OF EACH PORTFOLIO OF THE FIVE STOCKS OF SSE A SHARES

\begin{tabular}{|c|c|c|c|c|c|c|c|c|c|c|}
\hline & $\boldsymbol{A}, \boldsymbol{B}$ & $\boldsymbol{A}, \boldsymbol{C}$ & $\boldsymbol{A}, \boldsymbol{D}$ & $\boldsymbol{A}, \boldsymbol{E}$ & $\boldsymbol{B}, \boldsymbol{C}$ & $\boldsymbol{B}, \boldsymbol{D}$ & $\boldsymbol{B}, \boldsymbol{E}$ & $\boldsymbol{C}, \boldsymbol{D}$ & $\boldsymbol{C}, \boldsymbol{E}$ & $\boldsymbol{D}, \boldsymbol{E}$ \\
\hline$R_{p}$ & 8.47 & 9.52 & 8.93 & 6.98 & 5.82 & 5.23 & 3.28 & 6.28 & 4.32 & 3.74 \\
\hline$\sigma_{p}$ & 5.74 & 4.61 & 4.18 & 3.84 & 3.02 & 2.79 & 3.16 & 3.04 & 2.96 & 2.85 \\
\hline $\mathrm{Cov}$ & 12.24 & 19.09 & 14.31 & 2.27 & 6.05 & 6.19 & 3.96 & 8.36 & 0.74 & 2.34 \\
\hline $\mathrm{R}$ & 0.66 & 0.97 & 0.97 & 0.09 & 0.53 & 0.72 & 0.27 & 0.91 & 0.05 & 0.20 \\
\hline
\end{tabular}

(1) We assume that the investor is a risk avoider in the hypothesis, so when the investor invests in an asset, we can conclude from TABLE II that the risk of investing in asset D is the lowest.

(2) When the investor chooses two kinds of assets for portfolio investment, we can conclude from TABLE III that when the correlation coefficient of the two assets is less than or equal to 0 , the investment risk can be reduced by a reasonable proportion of the two assets. The risk of portfolio is lower than the risk of individual investment, so when investors invest in two assets, the choice of $\mathrm{C}$ and $\mathrm{E}$ assets can reduce the risk.

\section{SUMMARY}

Through case analysis, we can conclude that when investing in securities in financial markets, using mathematical models to conduct risk measurement analysis, investors can choose assets with lower risk and reduce investment through the combination of different securities assets risk. Reasonable investment can greatly reduce investment risks, reduce the loss of assets of enterprises and investors, and facilitate the sound development of financial markets.

The mean variance model proposed by Markowitz is the basis of modern portfolio theory. Although there are many shortcomings in the application of reality, its risk pricing ideas and models are of pioneering significance in the field of risk measurement. With the deepening of research on risk measurement, the theory of risk measurement has been greatly developed, and researchers are constantly improving the risk measurement model to find the best risk measurement method. Therefore, the research of risk measurement theory still has a lot of room for development and is a major issue facing the academic community.

\section{REFERENCES}

[1] Cai Bingjing, Application of Markowitz Mean Variance Model in China's Stock Market [D]. Shanghai: Fudan University, 2012: 5-15. In Chinese

[2] Wang Jingjing, Portfolio Model Based on Mean-VAR [J]. Mall Modernization, early July 2009: 82-83. In Chinese

[3] Guan Meiying, Research on Portfolio Problem [J]. Jinshan, 2011, 4. In Chinese

[4] Wang Zheng, Portfolio Investment Decision Based on Earnings and Risk Satisfaction [D]. Tianjin: Tianjin University, 2003.In Chinese

[5] Zhou Lan, A Comparative Study of Value Investment and Modern Securities Portfolio Theory[J]. Finance \& Finance, 2015, Vol. In Chinese

[6] Wang Qiang, Portfolio Theory Research and Empirical Analysis of Securities Portfolio [D]. Tianjin: Nankai University, 2000.In Chinese 